\title{
index
}

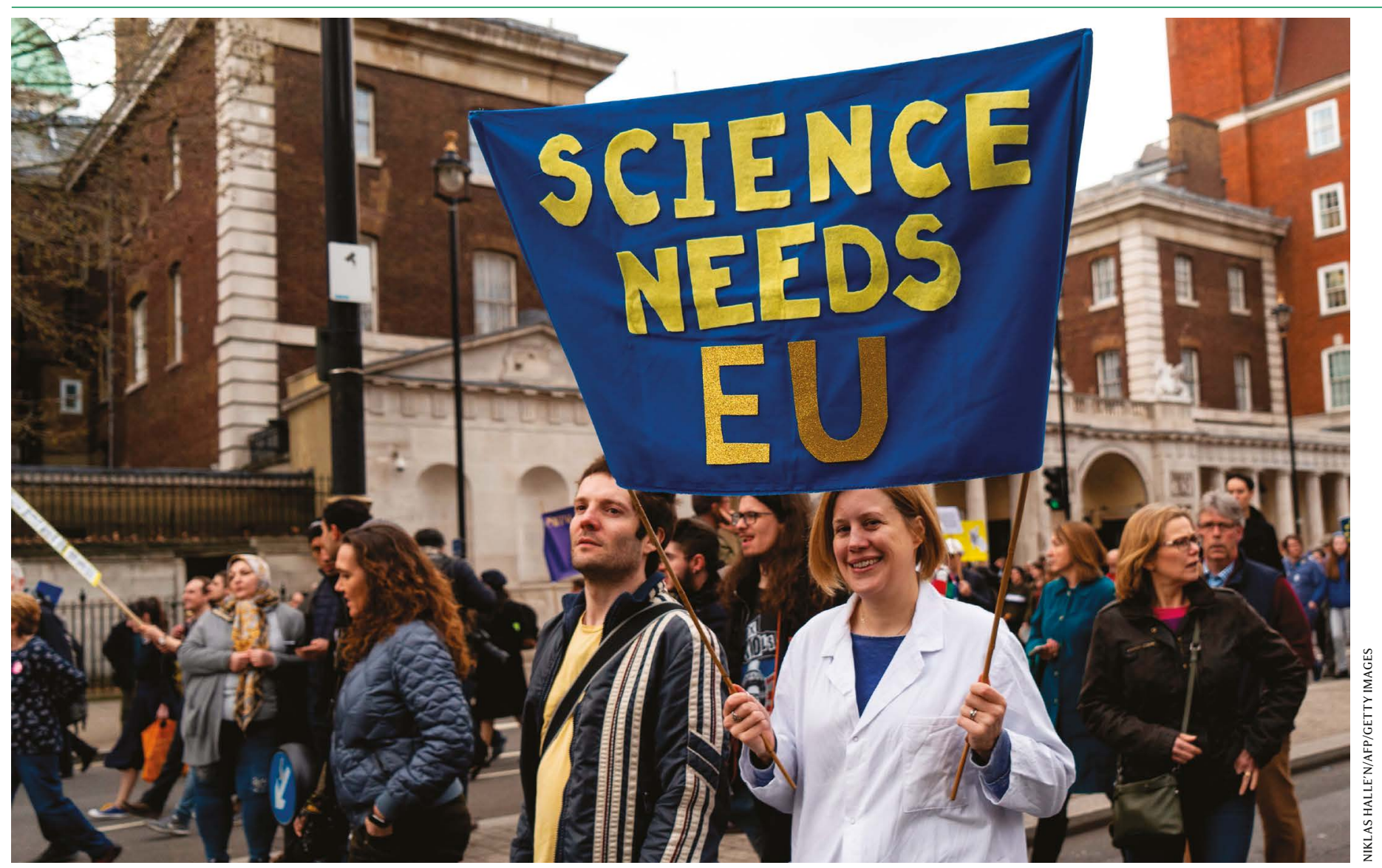

Protesters at a central London rally highlight the perils for science if the UK leaves the European Union.

\section{Brexit shadow hangs over EU partnerships}

\section{Uncertainty about the United Kingdom's role in EU science is damaging research networks. By Mark Peplow}

M ore than three years after UK citizens narrowly voted for their country to leave the European Union, scientists still face great uncertainty about how Brexit will impact their research.

The United Kingdom has already missed three deadlines for leaving the EU. Although the terms of the country's withdrawal from the bloc have been agreed, political manoeuvring has stalled the ratification of this treaty. To break the deadlock, the United Kingdom is gearing up for a general election on 12 December, and faces a new Brexit deadline of 31January 2020.

Even if the withdrawal treaty is ratified, it does little to resolve the country's long-term links with European science, which would be thrashed out in subsequent negotiations. If the United Kingdom leaves the EU next year without a deal in place to smooth the way, UK scientists could immediately lose access to the EU funding and collaborations that underpin their research.

This corrosive confusion is already reshaping collaborative networks. Some researchers are securing dual appointments that will enable them to straddle the United Kingdom and EU, and various UK universities have established partnership agreements with continental institutions so that their staff can continue to access EU funds.
“They want a Brexit-proof solution," says Kurt Deketelaere, secretary-general of the League of European Research Universities in Leuven, Belgium.

These changes could have far-reaching effects on existing partnerships. UK researchers collaborate more with researchers in other EU countries than any other region. According to the Nature Index, collaborative articles by UK-EU researchers in five leading journals (Nature, Science, Proceedings of the National Academy of Sciences, Nature Communications and Science Advances) grew by $36 \%$ between 2015 and 2018, although for reasons still not clear, the growth in collaborative articles 
across all 82 journals tracked by the index has stalled since before 2016, when the vote to leave the EU was taken.

The United Kingdom has also benefited significantly from EU research programmes. Huge schemes such as Horizon 2020, the EU's $€ 77$ billion (US $\$ 85$ billion) research and innovation programme, have provided a useful protocol for cross-border collaboration, facilitated by funding and helpful immigration arrangements. "That's a magic combination for doing research," says Graeme Reid, chair of science and research policy at University College London (UCL).

That success story is souring. In October, the Royal Society pointed out that the United Kingdom's annual share of EU research funding fell from $€ 1.49$ billion in 2015 to $€ 1.06$ billion in 2018 , largely caused by a reduction in grant applications from UK researchers. It also found that the number of researchers coming to the United Kingdom through the EU's Marie Skłodowska Curie Fellowships has fallen by 35\%, from 515 in 2015 to 336 in 2018.

\section{Magic combination}

"We have seen a dramatic drop in the number of leading researchers who want to come to the UK," says Venki Ramakrishnan, president of the Royal Society. "People do not want to gamble with their careers, when they have no sense of whether the UK will be willing and able to maintain its global scientific leadership."

Brexit comes at a crucial time for the future of EU science. The next research and innovation programme, Horizon Europe, will run from 2021 to 2027 and is expected to disburse about $€ 100$ billion. Almost half of this money is likely to go to large academia-industry collaborations in areas such as health, climate and food. The final budget and other details should be agreed by the end of 2020 .

If Brexit goes ahead with a withdrawal agreement in place, most researchers hope it will pave the way for the United Kingdom to participate in Horizon Europe as an associate member, an option the UK government says it will consider. This might involve paying into the central fund, so that UK researchers can apply for grants in the same way as EU members, albeit with little influence over the programme's strategy.

Leaving without a deal would probably stymie the chances of associate membership altogether, and leave a huge question mark over the future status of the $17 \%$ of scientists working in the United Kingdom who are from other EU countries. It would also have a sudden impact on UK participation in ongoing EU collaborations, particularly affecting UK researchers responsible for the management and finance of EU projects.
Peter Coveney, a computational scientist at UCL, coordinates two major projects that apply advanced computing to biological modelling, backed by $€ 12$ million in Horizon 2020 funding. In September, helearnt that the European Commission would ask UK project coordinators to step down in the event of a no-deal Brexit. To counter that, Coveney is ready to move the management of his projects to the continent. In March, he accepted a professorship in applied high-performance computing at the University of Amsterdam in the Netherlands, which he holds in addition to his existing UCL roles. "It's a Brexit mitigation strategy," he says.

Leading UK universities are adopting a similar approach, signing cooperation agreements with partners in continental Europe to intensify collaboration, establish joint research programmes and exchange staff and students. The University of Cambridge has partnered with the Ludwig Maximilians University of Munich in Germany, for example, and the University of Oxford has established an office in Berlin to facilitate partnerships with institutions there.

Some regions of the United Kingdom are particularly vulnerable to Brexit, and may struggle to adapt. Northern Ireland, for example, depends heavily on collaborations with partners from the Republic of Ireland, a separate

\section{“There's no way that Brexit won't have some negative impact on research collaboration."}

country and EU member state. “Sixty-three per cent of Horizon 2020 applications from researchers in Northern Ireland involved a partner from the republic," says Gerry McKenna, who chairs the Royal Irish Academy's NorthSouth Committee, which is concerned with collaboration across the Irish border. “There's no way that Brexit won't have some negative impact on research collaboration."

Amid these damage limitation efforts, Reid has been looking farther afield for ways to diversify the United Kingdom's research collaborations. He and statistician, Adrian Smith, who leads the London-based Alan Turing Institute, have written a report for the UK government that outlines opportunities for international collaboration if the country decides not to associate with Horizon Europe. Published on 5 November, the report suggests measures such as dedicated funding streams to enhance global collaboration, and new fellowships to attract talent to the United Kingdom. Reid hopes that the report will demonstrate that there are alternatives to traditional EUfocused collaborations.

The UK government has also tried to reassure the domestic research community with a string of policy announcements, such as reaffirming a commitment to increase national spending on research and development to at least $2.4 \%$ of GDP by 2027.

It also said that international students will be allowed to remain in the country for up to two years aftergraduation, so they can seek employment in the United Kingdom, and promised fast-track visa routes for foreign researchers. "I think that's an enormous step forward," says Martin Smith, a policy manager at Wellcome.

\section{Fast track}

However, the UK government's rhetoric has focused on attracting 'the brightest and best' from abroad. Smith says the new visa systems must cover all levels of the scientific workforce, including lab technicians and postdoctoral researchers, and adds that the costs of the system will be a key issue for early-career researchers.

If there is a no-deal Brexit, the UK government has promised that it will honour funding for all successful competitive UK bids to Horizon 2020 up to the end of next year, potentially costing hundreds of millions of pounds. But this overlooks the contribution of other EU funding streams.

EU structural funds, for example, are used to boost the economic development of EU regions that may be lagging behind, by investing in projects that can enhance innovation and create jobs.

"Structural funds have been crucial in building up the research base in Northern Ireland to an internationally competitive level," says McKenna. Several research facilities in Northern Ireland depended on such structural funding, he says, including the Northern Ireland Science Park.

Funding aside, the United Kingdom may simply become less attractive to international researchers if it adopts a hostile stance towards the EU during future negotiations. "This is not just a financial equation," says Reid. "An environment that is welcoming and nurturing is critical."

Deketelaere says that top researchers are already choosing to take their research out of the country. "In continental Europe, we're seeing an enormous influx of unsolicited applications for jobs in our universities, from excellent people," he says. This reshaping of the research landscape could become Brexit's lasting legacy for science.

Mark Peplow is a science writer based in Cambridge, UK. 